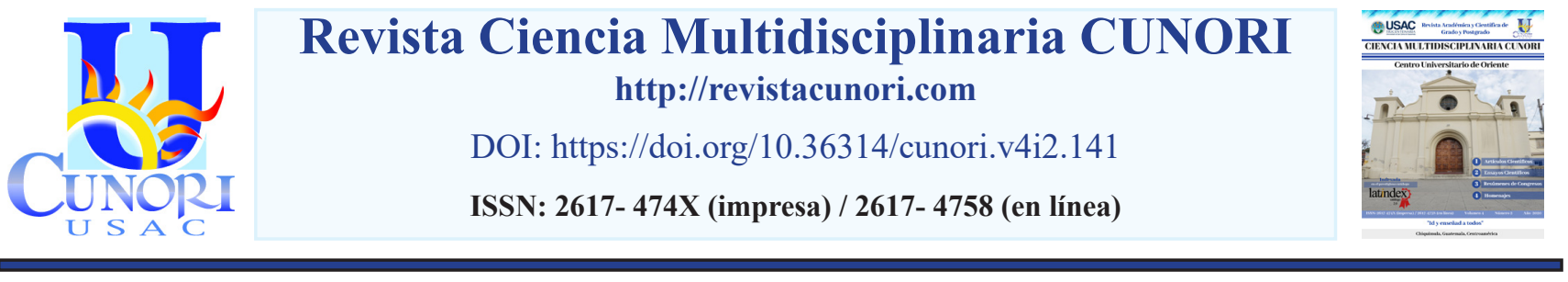

Referencia del ensayo

Paiz-Varela, R. (2020). Comienzo y origen de la filosofía: el asombro. Revista Ciencia Multidisciplinaria Cunori, 4(2), 163-170 . https://doi.org/10.36314/cunori.v4i2.141

\title{
Comienzo y origen de la filosofía: el asombro
}

\section{Beginning and origin of philosophy: the astonishment}

\author{
Rocael Paiz Varela \\ Universidad de San Carlos de Guatemala \\ https://orcid.org/0000-0003-0528-4869
}

Recibido: 18 de febrero de 2020 / Revisado: 25 de febrero de 2020 / Aceptado: 25 de mayo de 2020

Disponible en internet el 30 de octubre de 2020

Resumen

*Autor para correspondencia.

Correo electrónico:rpaiz@fahusac.edu.gt

— scribir y explicar todo aquello que se pueda relacionar con el asombro, vinculándolo con el comienzo y origen de la filosofía

- 1 pareciera ser una actividad quizá bastante comentada en otro lugar; en otro momento y en otro tiempo. Sin embargo, la libertad del pensamiento filosófico permite expresar otras opiniones, otras ideas y otras consideraciones, sino repetitivas, desde otras perspectivas y de otras formas. Diferentes pensadores han realizado investigaciones al respecto, pero pareciera que unos y otros, por diferentes caminos, llegan al mismo lugar. En el presente artículo se pretende ahondar en cada uno de esos tres temas con el objeto o la finalidad de esclarecer de manera clara el significado lógico, filosófico, real e histórico de este para relacionarlos en forma directa con la filosofía, su comienzo y su origen.

Palabras clave: duda, asombro, admiración, estupor, mito

\section{Abstract}

$\mathrm{W}$ riting and explaining everything that can be related to amazement, linking it to the beginning and origin of philosophy, seems to be an activity perhaps quite commented elsewhere; at another time and at another time. However, the freedom of philosophical thought allows to express other opinions, other ideas and other considerations, if not repetitive, from other perspectives and in other ways. Different thinkers have carried out research in this regard, but it seems that both, by different routes, arrive at the same place. In the article, it is intended to delve into each of these three themes with the object or purpose of clearly clarifying the logical, philosophical, real and historical meaning of this to relate them directly to philosophy, its beginning and its origin.

Keywords: doubt, amazement, admiration, stupor, myth 


\section{Introducción}

Todos los filósofos, desde la antigüedad hasta nuestro tiempo posmodernista, tienden a la universalización del asombro como el origen de la filosofía. Es más, también, se asocia el asombro con la admiración y la duda, como la trilogía que origina y comienza todo el quehacer filosófico. Como estudiante de la maestría y amante de la filosofía considero que tratar sobre el primero de los temas para enfocarlo desde otros puntos de vista. Es sumamente interesante para aquellos que hemos hecho de la filosofía una forma de vida y una forma diferente de observar los acontecimientos que día a día ocurren y no dejan de asombrarnos para luego indagar su por qué, cosa que hace primordial e indispensable el pensamiento filosófico.

\section{Contenido}

\section{El asombro y diversas concepciones}

El día que los hombres o los seres humanos, mejor dicho, dejen de asombrarse por lo que ocurre a su alrededor, por los acontecimientos que a diario se vive y por las cosas que suceden en la vida, en ese momento se termina la idea de filosofar y con ello asistiremos a la muerte de la filosofía misma.

Una gran mayoría de nuestros conciudadanos, jóvenes, especialmente, viven en una burbuja que recibe el nombre de estado material; que su única preocupación es la moda; que transitan en un mundo de codicia y ambición, que solo están interesados en lujos y comodidades; que ambicionan poder, sin importar cómo y que viven inmersos en el fétido y pantanoso problema del desear, han perdido la capacidad de asombrarse ante lo que sucede en su entorno social y a preguntarse el porqué de esos acontecimientos. ¿A qué se refiere el asombro?, o, ¿qué actitudes causa este en el ser humano?, pues estas pueden ser tales como: confusión, estupor, turbación, aturdimiento, espanto, sorpresa, pasmo, susto, conmoción. ¿Qué es el asombro?, ¿qué representa en la vida del filósofo y de la filosofía misma? Veamos las siguientes anotaciones al respecto:

El asombro es un estado o sentimiento que normalmente afecta a las personas y que se desencadena tras apreciar algo totalmente fuera de lo habitual. Digamos que la anormalidad que ostenta algo, ya sea para bien o para mal, o por ejemplo cuando alguien hace algo que jamás se hubiese esperado que lo termine haciendo, son algunas de las cuestiones que pueden derivar en el asombro de alguien. Se trata de una sensación bastante normal y corriente entre las personas, o sea, no es algo que difícilmente se experimente ni mucho menos, todo lo contrario, normalmente nos asombramos con diversas cuestiones que ocurren.

Ana María Sandoval, en su libro «Filosofía» (2019), P 5, escribe que: Platón dijo que el origen de la filosofía es una actitud muy humana: el asombro. Cuando contemplamos las estrellas o el atardecer en la playa, o nos maravillan las perfectas y pequeñas manos de un bebé, nuestras mentes despiertan, nuestros sentidos se abren y nos ponemos en contacto pleno con el mundo. Después del asombro viene la curiosidad, el interés, el deseo de conocer, de descubrir por qué los astros brillan, por qué el cielo se tiñe de rojo en el ocaso o por qué el mundo es como es. Con el interés llegan las dudas. Sometemos a juicio 
nuestras creencias y suposiciones, investigamos las causas de lo que ocurre hasta que nos topamos con los límites que desde la antigüedad ha encontrado la razón, entonces, sobreviene la conciencia de nuestra finitud, de nuestra pequeñez, en tres palabras: nuestra situación humana. ¿Cómo actuamos a partir de esa toma de consciencia? Esta respuesta es individual y cada uno elige el camino que quiere seguir.

Javier Sánchez Collado, en su «Introducción a la Filosofía» (2013) p 7, acerca del asombro afirma: Quien está asombrado, busca, tiene esperanzas y empeño por encontrar, aunque sea difícil (les lleva a saber más, aunque nunca acaben de saber del todo: de hecho cada vez están más convencidos de que saben menos, pues a medida que avanzan no paran de descubrir cosas asombrosas). El estupefacto no busca, carece de empeño o interés por encontrar y acaba refugiándose en las reglas de lo que sabe hacer, cosas repetitivas que no le planteen problemas. Si no se sale habitualmente del estupor se acaba siendo un estúpido, que es una forma de ignorancia. Se deja de ver que haya algo "extraño" en las cosas: las cosas son así, y ya está: “¡Las manzanas caen al suelo, porque sí, no hay más que averiguar!”, le hubiera dicho un ignorante a Newton. Con frecuencia quien es ignorante desprecia al sabio.

Aristóteles, citado por Julián Marías en su libro «Historia de la Filosofía» (1980) p 3 se refiere a lo siguiente: Por el asombro comenzaron los hombres, ahora y en un principio, a filosofar, asombrándose primero de las cosas extrañas que tenían más a mano, y luego, al avanzar así poco a poco, haciéndose cuestión de las cosas más graves tales como los movimientos de la Luna, del Sol, de los astros y la generación del todo. El mismo autor, p 3 y 4 continúa diciendo: Tenemos, pues, como raíz más concreta del filosofar una actitud humana que es el asombro. El hombre se extraña de las cosas cercanas, y luego de la totalidad de cuanto hay. En lugar de moverse entre las cosas, usar de ellas, gozarlas o temerlas, se pone fuera, extrañado de ellas, y se pregunta con asombro por esas cosas próximas y de todos los días, que ahora, por primera vez, aparecen frente a él, por tanto, solas, aisladas en sí mismas por la pregunta: «¿Qué es esto?» En este momento comienza la filosofía.

Antonio Gómez Ramos en su obra «Asombro, experiencia y forma: los tres momentos constitutivos de la filosofía» (2007) p 5 expone que: El asombro filosófico tiene el carácter de un arjé, que sostiene y domina la actividad de la filosofía, que mantiene el extrañamiento primero de la perplejidad y hace que la filosofía sea, en verdad, ese extrañamiento. El asombro como arjé hace de la filosofía tenga también algo de páthos. No es el padecer que sufre quien se encuentra aguijoneado por la infinita curiosidad de saber muchas cosas y encontrar muchos porqués. Sin duda, el páthos, y la curiosidad forman parte del pensamiento; todo el que haya pasado por la experiencia de la lectura o discusión filosófica ha sentido cómo tenía que dejarse llevar por los problemas, verse afectado por las muchas perspectivas del asunto, ha quedado "mordido por los discursos", como decía Platón en el Fedro. Pero, en el páthos, se trata de un temple de ánimo, una Stimrnung, una disposición particular del espíritu que no termina una vez que empieza el proceso de respuestas, y que en cierto modo, tal vez, sea ya indiferente a él.

Leonardo Ordoñez en su libro titulado «Notas para una filosofía del asombro» (2013) p 139 hace referencia a este diciendo: Desde sus orígenes la filosofía se ha visto a sí misma como hija del asombro. 
En la formulación griega de esta venerable concepción, el «amor por el saber» nace de la sensación de descubrimiento que el ser humano experimenta frente a las cosas en el momento en que las contempla en toda su plenitud. Desde luego, las cosas están siempre ahí, pero no son plenamente percibidas por nosotros. Quizá por distracción, por falta de interés, por debilidad de nuestro aparato generador de imágenes del mundo, o quizá incluso porque la realidad podría consistir no sólo en lo que se presenta sino también -y sobre todo- en lo que yace fuera del alcance de nuestros sentidos, la esencia de las cosas escapa a nuestra manera normal de percibirlas. Pero cuando esa esencia hace acto de «presencia» experimentamos asombro. Entonces hemos dado el primer paso en el camino del pensamiento.

Para terminar con el tema del asombro es necesario recurrir en última instancia a Jeannet Ugalde Quintana, quien en su libro «El asombro, la afección originaria de la filosofía» (2013) p 168 se refiere al asombro diciendo: El tema del asombro aparece en los primeros filósofos que intentaron realizar una definición de la filosofía, establecer sus fronteras y brindar una explicación de su nacimiento. Una cuestión importante es que tanto para Platón como para Aristóteles, quienes intentaron por primera vez realizar la tarea de delimitar la filosofía y ahondar en sus orígenes, la filosofía encuentra su nacimiento en un pathos o estado del alma que lleva a quien lo padece a la búsqueda del conocimiento. Así, para ambos filósofos, el interés por la filosofía proviene de un estado que predispone al conocimiento filosófico y que se caracteriza por cierta pasividad. El asombro es el estado a partir del cual se originaron la filosofía, el mito y el conocimiento en general. Sin embargo, aunque constituye el origen de la investigación de los primeros principios y de todo el saber, el asombro surge en el alma (la cual es considerada como el principio activo en el hombre) de forma involuntaria, siendo un estado que esta experimenta ante la percepción de lo existente.

\section{Comienzo y origen de la filosofía}

Karl Jaspers, psiquiatra y filósofo existencialista alemán, en el capítulo II, «Los orígenes de la filosofía» de su libro «La filosofía desde el punto de vista de la existencia» (1984) p 15 aclara que: Comienzo no es lo mismo que origen. Por comienzo se entiende el momento histórico en que los hombres empezaron a filosofar, es un dato convencional pues se refiere a un tiempo y un espacio determinados, el lugar es Grecia -Jonia, Elea o Mileto- y el tiempo se ubica en el siglo VII a. C., es decir que la historia de la filosofía como pensar metódico y sistemático tiene sus comienzos hace más de dos mil quinientos años. También hay que aclarar que en el comienzo no hay una distinción clara entre filosofía y ciencia, solo posteriormente comienza su diferenciación.

También indica, ahora bien, por origen se entiende la fuente de la que surge en todo tiempo el impulso que mueve a filosofar. Únicamente gracias a él resulta esencial la filosofía actual en cada momento y comprendida la filosofía anterior. Este origen es múltiple. Del asombro sale la pregunta y el conocimiento; de la duda acera de lo desconocido, el examen crítico y la clara certeza; de la conmoción del hombre y de la conciencia de estar perdido, la cuestión de si propio. Representémonos ante todo estos tres motivos. Jaspers en su libro titulado «La Filosofía» distingue tres orígenes del filosofar: el asombro, la duda y las situaciones límites. Del asombro sale la pregunta y la necesidad de responder, de la duda acerca de lo conocido sale el examen crítico que deriva en una posible certeza; de las situaciones límites (conmoción) del hombre sale la pregunta por su propio ser. Estos son comunes a todos los hombres. 


\section{¿Dónde se originó la filosofía?}

La filosofía existe desde hace más de dos mil años. Apareció en Grecia en el siglo VI a.C. Se dice que uno de los 7 sabios de la filosofía griega fue Tales de Mileto y que es el primer filósofo y padre de la filosofía por haber sido el primero en dar una explicación racional sobre el origen del universo.

Platón y Aristóteles dicen que en la filosofía su punto de partida es el asombro lo que quiere decir que el asombro es la disposición humana por la cual nos paramos, nos detenemos, frente a las cosas y nos preguntamos ¿por qué las cosas son así y no de otro modo? Algunos historiadores de la filosofía sitúan el origen de la misma en Jonia y Elea, especialmente, colonias griegas del Asia menor. Los filósofos jónicos confunden la filosofía con la física. Tratan de encontrar el origen de las cosas tratando de encontrar el principio inmutable para explicar la variedad de los fenómenos que ocurren a diario en la naturaleza. Por esta razón los filósofos jónicos son llamados naturalistas. Dentro de estos podemos encontrar a Tales de Mileto, Anaximandro y Anaxímenes.

La escuela pitagórica -fundada en Crotona, Italia, a donde Pitágoras huyo en el 532 a. C.- introduce dentro del pensar y quehacer filosófico a la disciplina de las relaciones cuantitativas, o sea, a las matemáticas, que se desarrollan de tal forma que pronto han de aparecer como una disciplina aparte o como una disciplina independiente. Esta escuela afirma que la explicación de los fenómenos no puede encontrarse en la materia misma, concreta y sensible, sino en sus relaciones cuantitativas. Por esta razón es que los pitagóricos consideran al número como la esencia acerca del origen de todo cuanto existe.

La escuela Eleática, por su parte, significa un avance en el sentido de la abstracción. Considera el principio de todo lo existente como algo inmutable que no es percibido por nuestros sentidos y nada tiene que ver con la inteligencia. En lugar del principio sensible de los jónicos, concibe un principio inteligible, negando con ello, la realidad del mundo de los fenómenos que es solo apariencia y, por lo tanto, el "lo que no es" o el "no ser". Tiempo después aparece otro filósofo llamado Heráclito de Efeso quien vino a establecer una relación, un puente o una similitud entre las dos escuelas por muchos años opuestas. Indicaba que no era posible negar la existencia del mundo de los fenómenos. Se da a la tarea de identificar el puro ser abstracto con el no ser, referido al mundo sensible negado por los eleáticos. Afirma que lo único existente es el cambio, el "devenir", pues las cosas no son algo inmutable, sino que se trasforman, devienen, cambian, pasan. "Todo pasa como un río", es su célebre aforismo. Este filósofo de la antigüedad considera que lo que da impulso a ese eterno devenir es el calor que da vida a todo lo que existe.

Carlos Aldana Mendoza, en su libro «Filosofía para nuestro tiempo» (2010), página 45, cita: Sepamos que la palabra "filosofía" empezó a utilizarse hasta después que se usaron las palabras "filósofo o filosofar". Se usaba el término filósofo para referirse a hombres muy estudiosos que poseían conocimientos sobre los distintos hechos de la vida humana y social. Se atribuye la invención del concepto a un señor que no comía carne animal, que daba clases en una cueva, detrás de una cortina. Ese señor fue Pitágoras, quien vivió entre los años 580 y 500 a. C. Él fue el primero en llamarse a sí mismo "filósofo". 
García González, en su «Filosofía, ciencia e ideología» (1985) p 14 indica: En cuanto al nombre de "filósofo", ya indicamos que Pitágoras fue el primero quien se lo impuso, llamándose así, estando en conversación familiar en Sición, con Leantes. Antes, la filosofía se llamaba sabiduría y sabio el que la profesaba habiendo llegado a lo sumo de su perfección; pero el que se dedicaba a ella se llamaba filósofo, aunque los sabios se llamaban también sofistas y aún sus poetas. Como sabios fueron juzgados Tales, Solón, Periandro, Cleóbulo, Quilón, Biantes y Plutarco (Los 7 sabios).

Aldana Mendoza - citado anteriormente- al respecto afirma: Lo que sí parece claro es que la filosofía se origina como reflexiones sobre el mundo, tanto natural como humano. Esto significa que surge por la curiosidad humana de averiguar sobre la realidad en que vive. Fue así que su admiración o miedo por lo que veía dio paso a la creación de reflexiones que con el paso del tiempo se fueron organizando de mejor manera, se fueron ordenando y utilizando para el estudio. Resumiendo esta cuestión podríamos concluir en que La filosofía surgió como un ejercicio de la razón humana, que buscaba el saber. Para ello, cultivaba el asombro, rechazaba opiniones falsas y ejercía la crítica de la ignorancia y la superstición. Pero la filosofía no es solo un saber que proporciona conocimiento teórico, sino que influye en la vida práctica y busca la belleza y la felicidad. Los primeros filósofos occidentales vivieron en Grecia en el siglo VI a. C.

\section{Y. ¿cómo nació la filosofía?}

Alex Persello, Director del Instituto Americano de Formación e Investigación, IAFI, de Argentina indica en su artículo «El origen de la filosofía, filosofía para no filósofos» (sf) p 1: la filosofía no tiene historia. No es una acumulación de conocimientos que cada vez es mayor y nos van dejando el panorama más claro. La filosofía no funciona así. Un filósofo actual puede contradecir todo lo que se dijo hace 2000 años, mientras que otro puede afirmarlo. A diferencia de las matemáticas, que una teoría se apoya sobre otra, el conocimiento filosófico se desarrolla por sí solo, sin basarse en historias o demostraciones anteriores. Esto me conduce al segundo aspecto: Todas las ciencias parten de un supuesto. Un supuesto o presupuesto, es algo que no se cuestiona. Que es aceptado sin posibilidad al cuestionamiento. Cualquier teórica matemática, asume que $2+2$ es 4 . No parte de cuestionar esta premisa. Por el contrario, la filosofía cuestiona absolutamente todo. Y podría decir que $2+2$ es igual a 4, pero no idéntico. 2 es un número y 4 es otro número, y que la suma de ambos sea 4 , no implica el principio de identidad. Identidad significa mismidad. Todo lo que no es idéntico, se denomina pues diferente. En conclusión, $2+2$ no es 4 .

Por lo general los filósofos griegos han considerado que la filosofía nace con Tales de Mileto allá por el siglo VII a. C., pero no se consideraba necesario explicar cómo se había producido ese surgimiento de una nueva forma de pensamiento. Durante mucho tiempo los mitos fueron suficientes para explicar el mundo y los fenómenos. El hombre primitivo no se preocupaba por averiguar la razón de cuanto sucedía y de cuanto existía. Se contentaba con encontrar la respuesta más simple y a culpar a los dioses o relacionarlos con todo cuanto ocurría en su entorno social. El mito es animista, mágico, recurre a lo invisible como fundamento de lo visible, acepta lo sobrenatural y lo extraordinario. La cosmología de los primeros filósofos modifica su lenguaje y cambia de contenido: en lugar de narrar los acontecimientos sucesivos, define los primeros principios constitutivos del ser; en lugar de presentarnos una lucha de dioses nos ofrece un intercambio mecánico de procesos o fenómenos naturales. 
La filosofía, pues, si bien enraizada en el mito, parece ser una creación original del pueblo griego. Su rechazo de lo sobrenatural, de lo mágico, de la ambivalencia, son signos de una racionalidad que difícilmente podemos encontrar en otras formas de pensamiento anterior. En algún momento de la historia, algunos pensadores se atrevieron a cuestionar los mitos y a buscar nuevas formas de pensamiento que tuvieran validez en sí mismas y que a diferencia de las ideas mitológicas, pasaran la prueba de un pensamiento que únicamente buscara la verdad.

Según el Diccionario Filosófico Marxista escrito por M. Rosental y P. Ludin, (1939) p 222, se considera que: el paso del mito al logos se dio por un proceso de secularización y por un proceso de abstracción del pensamiento. Rompía así el pensamiento griego las estructuras propias del pensamiento mítico y los sustituyó por el lógico dando lugar a la filosofía y el pensamiento histórico ya que la filosofía y la historia comparten esa racionalidad, son discursos racionales. La lógica mítica era ambigua porque se movía en dos planos: el natural y el sobrenatural de manera que el mito explicaba los fenómenos naturales con argumentos donde intervenían elementos sobrenaturales. Como los rayos (elemento natural) argumentado como que era la cólera de Zeus. Los estudios de Mircea Eliade han puesto de manifiesto que el pensamiento mítico arcaico hacía imposible que el hombre pudiera asumir la historicidad y, por ende, impedía el nacimiento de la historia. Una de las razones es porque el pensamiento mítico solo daba importancia a los dioses y no a los hombres y era imposible desarrollar la historia sin tener en cuenta los aspectos mundanos.

\section{Conclusión}

En rasgos generales podemos concluir en que La filosofía surgió como un ejercicio de la razón humana, que buscaba el saber. Para ello, cultivaba el asombro, rechazaba opiniones falsas y ejercía la crítica de la ignorancia y la superstición. Pero la filosofía no es solo un saber que proporciona conocimiento teórico, sino que influye en la vida práctica y busca la belleza y la felicidad. Los primeros filósofos occidentales vivieron en Grecia en el siglo VI a. C. La filosofía no nació con el nacimiento de la vida, la filosofía se inició cuando el hombre fue capaz de abandonar el mito e indagar o preguntarse el porqué de lo que acontecía a su alrededor. El asombro resulta ser el origen de la filosofía y con ello, del pensamiento filosófico. Los filósofos jónicos reciben el nombre de naturalistas porque tratan de encontrar la explicación de cuanto acontece en la diversidad de fenómenos naturales o en la naturaleza misma. Los filósofos eleáticos niegan el mundo de los fenómenos exponiendo que el mundo fenoménico es solo apariencia y proponen un principio inteligible como causa única de cuanto ocurre. Heráclito de Efeso une a las dos escuelas antagónicas afirmando que no se podía negar el mundo sensible jonio y afirma que es el fuego o sea, el calor, el que da vida a todo lo que existe. El asombro es también admiración que nace en la contemplación de aquello que a nuestros ojos causa deleite. Certeza es la seguridad de algo mientras que la incertidumbre es el desconocimiento de lo que viene o de lo puede ocurrir. Para la mayoría de pensadores griegos, Tales es el creador de la filosofía. Pitágoras creo el término filósofo al llamarse así, él mismo. Dentro de los filósofos más importantes del pensamiento jónico figuran Anaximandro, Anaxímenes y Tales de Mileto ya que fueron considerados los principales filósofos presocráticos. Tales, Solón y Periandro son considerados tres de los 7 sabios de Grecia. 


\section{Referencias}

Aldana, C. Filosofía para nuestro tiempo. (2010) Editorial Piedra Santa, Guatemala C. A.

García, G. Filosofía, Ciencias e Ideología. (1985). Cuba: Científico-Técnica.

Jaspers, K. La Filosofía desde el punto de vista de la existencia. (1984), Fondo de Cultura Económica, Buenos Aires, Argentina.

Marías, J. Historia de la filosofía. (1980) 32ª Ed. Biblioteca de la revista de occidente, Madrid, España.

Ordoñez, L. Notas para una filosofía del asombro. (2013), Tinkuy No. 20. Universidad de Montreal, Canadá.

Persello. A. El origen de la filosofía, filosofía para no filósofos. (sf) Instituto Americano de Formación e Investigación, IAFI, Buenos Aires, Argentina.

Rosental, M. y P. Iudin. Diccionario Filosófico Marxista Soviético (1939), Editorial Séneca, Buenos Aires Argentina.

Sánchez, J. Introducción a la filosofía (2013) Editorial Gente Nueva. Habana, Cuba.

Sandoval, A. Filosofía (2019) 3ª Edición. Editorial Sandoval, Guatemala. C.A.

Ugalde, J. El asombro, la afección originaria de la filosofía (2013). Areté, Vol. 29 No. 1. Lima Perú. doi: https://doi.org/10.18800/arete.201701.007

\section{Sobre el autor}

\section{Rocael Paiz Varela}

Pedagogo y estudiante en proceso de graduación de la Maestría en Filosofía en Fahusac, Guatemala. Trabaja como Profesor Titular V en el Departamento de Pedagogía de la Facultad de Humanidades, USAC, Guatemala.

Copyright (c) Rocael Pais Varela

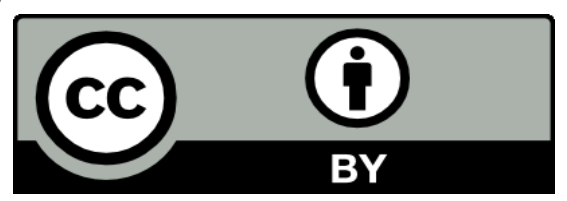

Este texto está protegido por una licencia CreativeCommons 4.0.

Usted es libre para compartir, copiar y redistribuir el material en cualquier medio o formato y adaptar el documento, remezclar, transformar y crear a partir del material para cualquier propósito, incluso comercialmente, siempre que cumpla la condición de atribución: usted debe reconocer el crédito de una obra de manera adecuada, proporcionar un enlace a la licencia, e indicar si se han realizado cambios. Puede hacerlo en cualquier forma razonable, pero no de forma tal que sugiera que tiene el apoyo del licenciante o lo recibe por el uso que hace. 